\title{
Implementation of Telephone-Based Secondary Preventive Intervention after Stroke and Transient Ischemic Attack - Participation Rate, Reasons for Nonparticipation and One-Year Mortality
}

\author{
Anna-Lotta Irewalla Lisa Bergström ${ }^{b} \quad$ Joachim Ögren $^{b} \quad$ Katarina Laurell $^{c}$ \\ Lars Söderström $^{d}$ Thomas Mooe $^{b}$ \\ ${ }^{a}$ Department of Public Health and Clinical Medicine, and Departments of ${ }^{b}$ Public Health and Clinical \\ Medicine at Östersund and ${ }^{\mathrm{C} P h a r m a c o l o g y}$ and Clinical Neuroscience at Östersund, Umeå University, \\ Umeå, and dUnit of Clinical Research Center, County Council of Jämtland, Östersund Hospital, \\ Östersund, Sweden
}

Key Words

Secondary prevention · Stroke · Transient ischemic attack · Socioeconomic status .

Implementation

\section{Abstract}

Background and Purpose: Patients who experience a stroke or transient ischemic attack (TIA) are known to be at high risk of subsequent vascular events, underscoring the need for secondary preventive intervention. However, previous studies have indicated insufficiency in the implementation of secondary prevention, emphasizing the need to develop effective methods of follow-up. In the present study, we examined the potential of implementing a telephone-based, nurse-led, secondary preventive follow-up in stroke and TIA patients on a population level by analyzing the participation rate, reasons for nonparticipation, and oneyear mortality. Methods: Between January 1, 2010 and December 31, 2011, all patients admitted to Östersund hospital, Sweden, and diagnosed with either stroke or TIA were considered for inclusion into the secondary preventive follow-up. Baseline data were collected at the hospital, and reasons for nonparticipation were documented. Multivariate logistic regression was performed to identify predictors of the patient decision not to participate and to explore independent associations between baseline characteristics and exclusion. A one-year followup of mortality was also performed; the survival functions of the three groups (included, excluded, declining participation) was calculated using the Kaplan-Meier estimator. Results: From a total of 810 identified patients, 430 (53.1\%) were included in the secondary preventive follow-up, 289 (35.7\%) were excluded mainly due to physical or cognitive disability, and 91 (11.2\%) declined participation. Age $\geq 85$ years, ischemic and hemorrhagic stroke, modified 
Rankin scale score $>3$, body mass index $\geq 25$, congestive heart failure, and lower education level were independently associated with exclusion, whereas lower education level was the only factor independently associated with the patient decision not to participate. Exclusion was associated with a more than 12 times higher risk of mortality within the first year after discharge. Conclusion: Population-based implementation of secondary prevention in stroke and TIA patients is limited by the high prevalence of comorbidity and a considerable degree of disability. In our study, a large proportion of patients were unable to participate even in this simple form of secondary preventive follow-up. Exclusion was associated with substantially higher one-year mortality, and education level was independently associated with physical ability as well as the motivation to participate in the secondary preventive follow-up program.

(C) 2014 S. Karger AG, Basel

\section{Introduction}

Patients who experience a stroke or transient ischemic attack (TIA) are known to be at high risk of subsequent vascular events [1-4], underscoring the need for secondary preventive intervention. Today, there are several evidence-based methods of secondary preventive treatment [5], and estimates suggest that an $80-90 \%$ risk reduction could be achieved by optimizing treatment combining different approaches [6]. Evidence of secondary preventive medical treatment is, however, to a great extent based on clinical trials that are generally performed in selected populations [7, 8]. Experience from population-based studies using a multifactorial secondary preventive approach is, to our knowledge, lacking among stroke and TIA patients. Similarly, knowledge regarding success in reaching set target values as defined in published guidelines $[9,10]$ is limited in an unselected stroke and TIA population.

In the EuroAspire survey, which included patients with coronary artery disease, the proportion of patients reaching the targets for blood pressure and cholesterol was 61 and $46 \%$, respectively [11]. International surveys of a similar size are lacking among cerebrovascular patients, but smaller national studies indicate that secondary prevention is equally unsuccessful in this population [12-14]. This suggests insufficiency in the implementation of secondary prevention, emphasizing the need to develop effective methods of follow-up that are simple enough to implement in clinical practice. Programs of intensified, multifactorial, secondary prevention among patients with type 2 diabetes [15], acute coronary syndrome $[16,17]$, and minor stroke/TIA [18] have previously shown promising results in terms of improved control of risk factors [15-18] and reduction of vascular events and mortality [15]. Implementing secondary prevention in an unselected stroke and TIA population has, however, not been studied, making it difficult to estimate the potential gain from intensified secondary preventive programs at a population level.

In Sweden, secondary prevention following stroke and TIA is initiated during hospitalization, and additional follow-up is usually performed by a general practitioner, a routine common in many countries. The NAILED (nurse-based age-independent intervention to limit evolution of disease after stroke) stroke risk factor trial is an on-going, population-based, randomized, controlled trial with two parallel groups. The trial will test the hypothesis that nurse-led telephone-based follow-up, in addition to usual care, is an effective method for promptly reaching set target values for blood pressure and blood lipids. In the present study, we focused on the feasibility of implementing this follow-up program on a population level. Our objectives were to analyze the participation rate, the reasons for nonparticipation including exclusion and the patients' decision not to participate, and the one-year mortality rate for excluded patients compared with included patients and patients declining participation. 


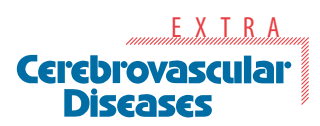

\begin{tabular}{l|l}
\hline \multicolumn{2}{l|}{ Cerebrovasc Dis Extra 2014;4:28-39 } \\
\hline DOI: $10.1159 / 000358121$ & $\begin{array}{l}\text { C 2014 S. Karger AG, Basel } \\
\text { www.karger.com/cee }\end{array}$ \\
\hline Irewall et al.: Implementation of Telephone-Based Secondary Preventive Intervention
\end{tabular}

Irewall et al.: Implemen
after Stroke and TIA

\section{Materials and Methods}

\section{Study Population}

The study participants were those considered for inclusion in the NAILED stroke risk factor trial between January 1, 2010 and December 31, 2011. Through a routine based on performed computed tomography scans, all patients admitted to Östersund hospital and diagnosed with either stroke or TIA were identified. A stroke event was defined in accordance with the WHO definition [19]. Both ischemic and hemorrhagic events were included, with the exception of subarachnoid hemorrhage. A TIA was defined as symptoms of stroke dissolving within $24 \mathrm{~h}$. Patients who died during hospitalization were excluded from the study.

Östersund hospital is the only hospital in the county of Jämtland and, with the exception of those in terminal care, all patients with symptoms of suspected stroke or TIA are referred there. The county constitutes a rural catchment area situated in the middle part of Sweden, and is inhabited by approximately 126,000 people.

\section{Study Design}

This was a nonparticipation study, focusing on the feasibility of telephone-based, nurseled, secondary preventive follow-up on a population level. During patients' hospitalization, specially trained study nurses collected baseline data, including clinical status, comorbidity and risk factors for all identified patients. A full list of descriptive variables is given in table 1. Data were gathered through patient interviews and further supplemented through review of the medical records.

Before discharge, all surviving patients were considered for inclusion into the randomized secondary preventive follow-up, i.e. the nurse-led, telephone-based follow-up, including titration of medications. For further details about the design of the intervention, readers are referred to the previously published study protocol [20]. Since the follow-up was to be conducted by telephone, patients were required to be physically and cognitively able to communicate over the telephone in order to be eligible for randomization. In addition, patients had to be able to visit their primary care facility (or the hospital if they lived nearby) to have a blood test for lipids and get a standardized blood pressure control measurement prior to each contact. Those participating in another on-going trial were excluded. The main reason for exclusion was carefully documented for each patient not eligible for randomization.

The study population was grouped as follows: (1) patients who were eligible for inclusion and agreed to be randomized into the secondary preventive follow-up comprised the 'included' group, (2) patients eligible for participation but who chose not to participate comprised the 'declining participation' group, and (3) patients not eligible for inclusion due to either severe physical or cognitive impairment or participation in another clinical trial comprised the 'excluded' group.

To address the prognosis after discharge, a one-year follow-up of mortality was performed on all patients. Information about mortal events and causes of death was obtained through the National Cause of Death Register. Mortal events were classified as cardiovascular or noncardiovascular. In cases where the information obtained through the National Cause of Death Register was insufficient to classify the cause of death accordingly, the information was further supplemented through review of the medical records. The study was approved by the regional ethics committee, Umeå University, Umeå, Sweden.

\section{Statistical Analysis}

Baseline characteristics for participants, excluded patients, and patients declining participation were compared using the $\chi^{2}$ test, Fischer's exact test, or independent-samples t test 


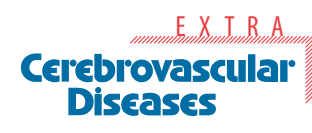

\begin{tabular}{|c|c|}
\hline \multicolumn{2}{|c|}{ Cerebrovasc Dis Extra 2014;4:28-39 } \\
\hline DOI: $10.1159 / 000358121$ & $\begin{array}{l}\text { (C) } 2014 \text { S. Karger AG, Basel } \\
\text { www.karger.com/cee }\end{array}$ \\
\hline
\end{tabular}

Table 1. Definition of variables

\begin{tabular}{|c|c|}
\hline Stroke & $\begin{array}{l}\text { Includes ischemic and hemorrhagic events except for subarachnoid } \\
\text { hemorrhage. An event was defined in accordance with the WHO } \\
\text { definition of stroke [19] }\end{array}$ \\
\hline Transient ischemic attack & Symptoms of stroke dissolving within $24 \mathrm{~h}$ \\
\hline Glomerular filtration rate & $\begin{array}{l}\text { Based on creatinine clearance calculated using the Cockcroft-Gault } \\
\text { formula }\end{array}$ \\
\hline Body mass index & $\begin{array}{l}\text { Calculated as the person's weight in kilograms divided by the square of } \\
\text { the person's height in meters }\end{array}$ \\
\hline Postbasic education & Educational level at least equal to upper secondary school \\
\hline Ischemic heart disease & $\begin{array}{l}\text { Previous diagnosis of acute myocardial infarction and/or performed } \\
\text { percutaneous coronary intervention and/or coronary artery bypass } \\
\text { graft }\end{array}$ \\
\hline Previous stroke & Previous diagnosis of cerebral infarction or hemorrhage \\
\hline Peripheral artery disease & $\begin{array}{l}\text { Previously diagnosed peripheral artery disease including atherosclerotic } \\
\text { aneurysms and carotid artery stenosis }\end{array}$ \\
\hline Congestive heart failure & Previous diagnosis of congestive heart failure \\
\hline Smoking & Current or former smoker \\
\hline Atrial fibrillation & Diagnosed previously or during the current hospitalization \\
\hline Hyperlipidemia & $\begin{array}{l}\text { Low-density lipoprotein cholesterol (calculated using the Friedewald } \\
\text { formula) } \geq 2.5 \text { or total cholesterol } \geq 4.5 \text {, or patient currently on } \\
\text { lipid-lowering medication }\end{array}$ \\
\hline Hypertension & Previous diagnosis of hypertension \\
\hline Diabetes & Previous diagnosis of diabetes mellitus \\
\hline Cardiovascular events of death & $\begin{array}{l}\text { Events of death registered in the National Cause of Death Register as } \\
\text { caused by any of the following: myocardial infarction, stroke, congestive } \\
\text { heart failure, cardiogenic shock, cardiac arrhythmia, pulmonary } \\
\text { embolism, aortic aneurysm rupture or peripheral artery disease }\end{array}$ \\
\hline
\end{tabular}

as appropriate. All tests were 2-sided, and statistical significance was determined at an alpha level of 0.05 .

To identify independent predictors of the patient decision not to participate, a multivariate logistic regression model was set up, comprising all patients eligible for inclusion and including all descriptive variables found to differ significantly between included patients and patients declining participation. A second multivariate model was constructed to explore independent associations between baseline characteristics and exclusion. This second model comprised all study participants and included all variables found to differ significantly between excluded patients and patients eligible for inclusion. Regardless of significant differences between groups, both models also included sex as a covariate. Associations were expressed as odds ratios (OR) with 95\% confidence intervals (CIs).

The Kaplan-Meier estimator, with the log-rank test for group comparisons, was used to assess the cumulative one-year survival of included patients, excluded patients and patients declining participation. Univariate logistic regression was applied to calculate the ORs for mortality, with the group of included patients as a reference category. 


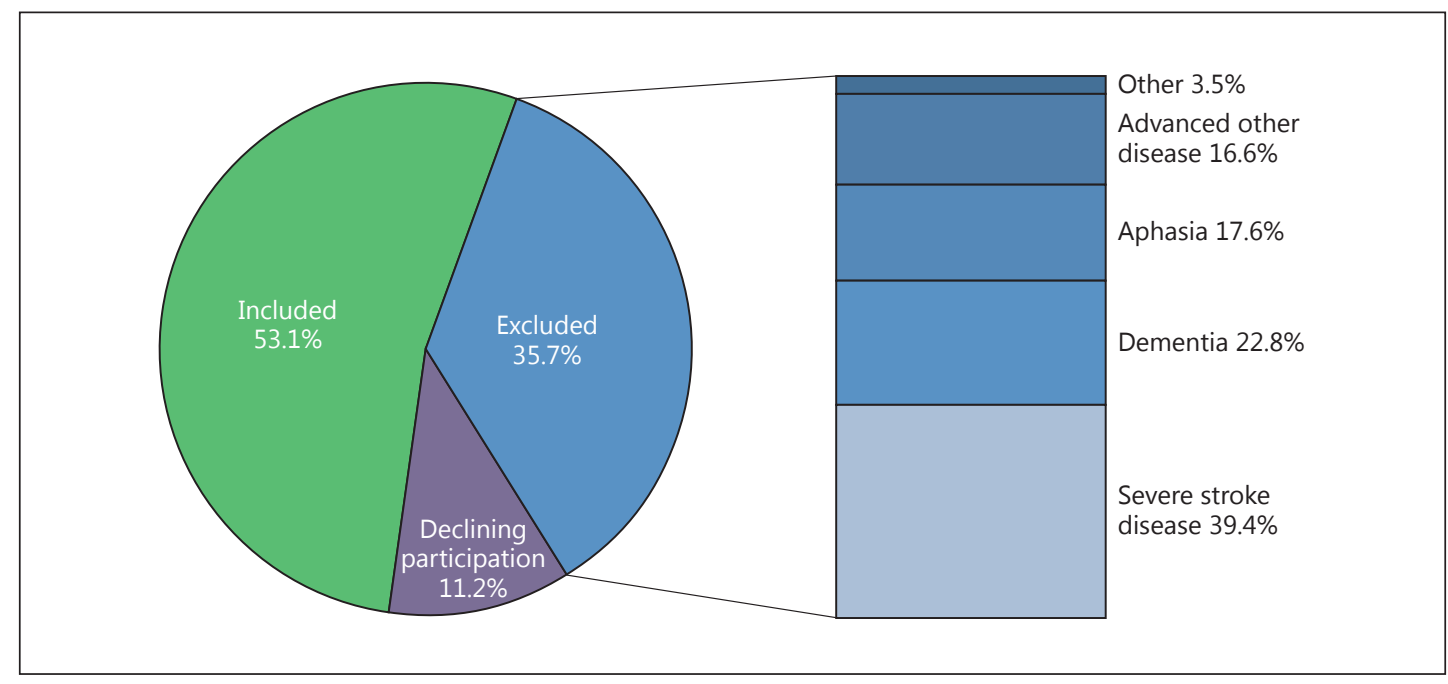

Fig. 1. Reasons for nonparticipation in the secondary preventive follow-up.

Continuous variables were categorized when used in regression analyses, and multicolinearity diagnostics did not show any serious multicolinearity between variables included in the multivariate models. All statistical analyses were performed using SPSS v. 20.0.

\section{Results}

\section{Study Participants}

During the inclusion period, 887 patients with stroke $(n=600)$ or TIA $(n=287)$ were identified. Seventy-seven $(8.7 \%)$ patients died during the initial hospitalization and were therefore excluded from further analyses. Of the surviving 810 patients, 430 (53.1\%) were eligible for inclusion and agreed to be randomized into the secondary preventive follow-up, whereas $91(11.2 \%)$ patients declined participation and 289 (35.7\%) were excluded. The reported main reasons for exclusion (fig. 1 ) were severe stroke disease ( $n=114,39.4 \%)$, dementia $(n=66,22.8 \%)$, aphasia $(n=51,17.6 \%)$, other severe disease $(n=48,16.6 \%)$, impaired hearing $(n=6,2.1 \%)$, and participation in another clinical trial $(n=4,1.4 \%)$.

\section{Baseline Characteristics}

Comparison of baseline characteristics between included and excluded patients confirmed substantial differences in terms of clinical status, comorbidity, and burden of risk factors (table 2). The group of excluded patients contained a larger proportion of stroke diagnoses as well as a larger proportion of patients with a modified Rankin Scale (mRS) score $>3$. Moreover, excluded patients were significantly older and had a lower mean glomerular filtration rate (GFR), mean body mass index (BMI), and education level measured as the proportion with an education level at least equal to upper secondary school. In terms of risk factors, atrial fibrillation and hypertension were more common among excluded patients, whereas current or former smoking was less common. Finally, excluded patients were more likely to have had a previous diagnosis of ischemic heart disease, stroke or congestive heart failure. 
Irewall et al.: Implementation of Telephone-Based Secondary Preventive Intervention after Stroke and TIA

Table 2. Characteristics of the study population

\begin{tabular}{|c|c|c|c|c|c|c|c|c|c|}
\hline & \multicolumn{2}{|l|}{ Included } & \multicolumn{2}{|l|}{ Excluded } & \multicolumn{2}{|c|}{$\begin{array}{l}\text { Declining } \\
\text { participation }\end{array}$} & \multirow[t]{2}{*}{$\mathrm{p}^{\mathrm{a}}$} & \multirow[t]{2}{*}{$\mathrm{p}^{\mathrm{b}}$} & \multirow[t]{2}{*}{$\mathrm{p}^{\mathrm{c}}$} \\
\hline & $\mathrm{n}$ & $\%$ & $\mathrm{n}$ & $\%$ & $\mathrm{n}$ & $\%$ & & & \\
\hline Subjects & 430 & 53.1 & 289 & 35.7 & 91 & 11.2 & & & \\
\hline Male & 234 & 54.4 & 146 & 50.5 & 48 & 52.7 & 0.304 & 0.771 & 0.711 \\
\hline Age, mean $\pm S D$, years & \multicolumn{2}{|c|}{$71.8 \pm 10.6$} & \multicolumn{2}{|l|}{$81.5 \pm 9.1$} & \multicolumn{2}{|c|}{$77.2 \pm 13.1$} & $<0.001$ & $<0.001$ & 0.004 \\
\hline Stroke & 273 & 63.5 & 263 & 91.0 & 64 & 70.3 & $<0.001$ & 0.215 & $<0.001$ \\
\hline Ischemic & 254 & & 234 & & 56 & & & & \\
\hline Hemorrhagic & 19 & & 28 & & 8 & & & & \\
\hline Unspecified & 0 & & 1 & & 0 & & & & \\
\hline \multicolumn{9}{|l|}{ GFR } & $<0.001$ \\
\hline $\begin{array}{l}\text { Mean } \pm \mathrm{SD}, \mathrm{ml} / \mathrm{min} \\
\mathrm{n}\end{array}$ & \multicolumn{2}{|l|}{$\begin{array}{l}81.7 \pm 32.1 \\
429\end{array}$} & \multicolumn{2}{|l|}{$\begin{array}{l}60.4 \pm 29.2 \\
281\end{array}$} & \multicolumn{2}{|l|}{$\begin{array}{l}68.5 \pm 34.5 \\
84\end{array}$} & $<0.001$ & $<0.001$ & 0.033 \\
\hline \multicolumn{10}{|l|}{ BMI } \\
\hline $\begin{array}{l}\text { Mean } \pm \text { SD } \\
\mathrm{n}\end{array}$ & \multicolumn{2}{|l|}{$26.8 \pm 4.3$} & \multicolumn{2}{|l|}{$\begin{array}{l}24.9 \pm 4.9 \\
275\end{array}$} & \multicolumn{2}{|l|}{$\begin{array}{l}25.8 \pm 4.3 \\
84\end{array}$} & $<0.001$ & 0.070 & 0.123 \\
\hline Postbasic education & $181 / 429$ & 42.2 & $37 / 266$ & 13.9 & $14 / 85$ & 16.5 & $<0.001$ & $<0.001$ & 0.560 \\
\hline Ischemic heart disease & 55 & 12.8 & 55 & 19.0 & 19 & 20.9 & 0.023 & 0.045 & 0.698 \\
\hline Previous stroke & 73 & 17.0 & 89 & 30.8 & 24 & 26.4 & $<0.001$ & 0.036 & 0.421 \\
\hline Peripheral artery disease & 21 & 4.9 & 15 & 5.2 & 3 & 3.3 & 0.853 & 0.782 & 0.580 \\
\hline Congestive heart failure & 21 & 4.9 & 52 & 18.0 & 8 & 8.8 & $<0.001$ & 0.140 & 0.036 \\
\hline Smoking & 206 & 47.9 & $94 / 283$ & 33.2 & $44 / 90$ & 48.9 & $<0.001$ & 0.865 & 0.007 \\
\hline Atrial fibrillation & $85 / 429$ & 19.8 & 106 & 36.7 & $20 / 90$ & 22.2 & $<0.001$ & 0.605 & 0.011 \\
\hline Hyperlipidemia & $310 / 323$ & 96.0 & $210 / 222$ & 94.6 & $65 / 69$ & 94.2 & 0.449 & 0.515 & 1.000 \\
\hline Hypertension & 262 & 60.9 & 214 & 74.0 & 69 & 75.8 & $<0.001$ & 0.007 & 0.735 \\
\hline Diabetes & 74 & 17.2 & 61 & 21.1 & 20 & 22.0 & 0.189 & 0.282 & 0.860 \\
\hline
\end{tabular}

$\mathrm{p}^{\mathrm{a}}, \mathrm{p}^{\mathrm{b}}$ and $\mathrm{p}^{\mathrm{c}}$ indicate significance for the following comparisons: included vs. excluded ( $\mathrm{p}^{\mathrm{a}}$ ), included vs. declining participation $\left(\mathrm{p}^{\mathrm{b}}\right)$, and excluded vs. declining participation $\left(\mathrm{p}^{\mathrm{c}}\right)$. For variables with missing values, the valid number of cases is given for each group.

Also, patients who chose not to participate differed from the excluded patients in several ways. The group who chose not to participate included a lower proportion of stroke diagnoses and had a lower proportion of patients with an mRS score $>3$. In addition, those who chose not to participate were younger and had a higher mean GFR, a higher proportion of current or former smokers, and a lower proportion of congestive heart failure as well as atrial fibrillation.

However, significant differences in baseline characteristics were also found when the group who chose not to participate was compared with the included patients. Compared with the included patients, those who chose not to participate were older and had a lower mean GFR as well as a higher prevalence of ischemic heart disease, previous stroke, and hypertension. Their functional status, measured as the proportion of those with an mRS score $>3$, was slightly poorer and the proportion with a higher education level was substantially lower.

\section{Independent Predictors of the Decision Not to Participate}

Having an educational level at least equal to upper secondary school emerged as a negative predictor of the decision not to participate in the secondary preventive follow-up. None of the other variables included in the model showed any significant association with the outcome (fig. 2). 
Irewall et al.: Implementation of Telephone-Based Secondary Preventive Intervention after Stroke and TIA

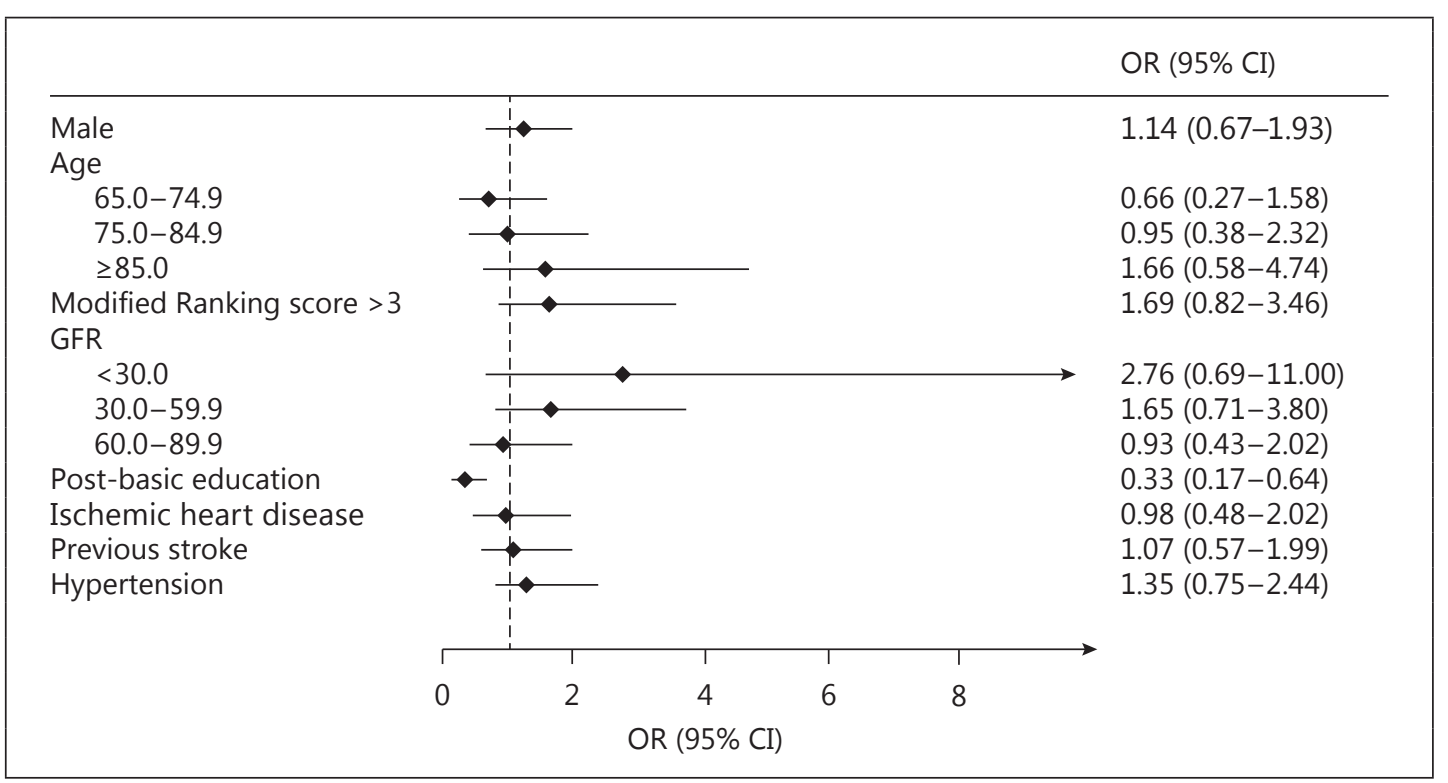

Fig. 2. Multivariate association with the decision not to participate. Age $<65$ years and GFR $\geq 90 \mathrm{ml} / \mathrm{min}$ were used as reference categories for age and GFR, respectively.

Independent Association between Baseline Characteristics and Exclusion

Age $\geq 85$ years, ischemic and hemorrhagic stroke, mRS score $>3$, and congestive heart failure were positively associated with exclusion, whereas having a BMI $\geq 25$ and an educational level at least equal to secondary school were negatively associated with exclusion (fig. 3).

\section{One-Year Mortality}

The one-year prognosis in terms of mortality differed substantially between included and excluded patients $(\mathrm{p}<0.001)$, whereas no significant difference in mortality was seen between included patients and patients declining participation $(\mathrm{p}=0.190)$. During the first year after discharge, a total of 130 patients died, 19 (4.4\%) in the included group, $104(36.0 \%)$ in the excluded group, and 7 (7.7\%) in the declining participation group.

As illustrated by the curves in figure 4 , the greatest difference in the mortality rate between included and excluded patients was observed during the first months. However, the mortality rate remained higher among excluded patients throughout the entire year of followup. Exclusion was associated with a more than 12 times higher risk of mortality within the first year after discharge $(\mathrm{OR}=12.16,95 \% \mathrm{CI}=7.24-20.43)$.

Cardiovascular disease accounted for $66.2 \%$ of the total one-year mortality. Cardiovascular death was significantly more common among excluded patients compared with included patients (74.3 vs. $42.1 \%, \mathrm{p}=0.005)$, whereas no significant difference was found between included patients and patients declining participation ( 42.1 vs. $42.9 \%, \mathrm{p}=1.000$ ).

\section{Discussion}

To maximize the participation rate, the NAILED stroke risk factor trial did not have any predefined exclusion criteria other than the estimated inability to participate in the secondary preventive program (or participation in another clinical trial). This provided us with the 
Irewall et al.: Implementation of Telephone-Based Secondary Preventive Intervention after Stroke and TIA

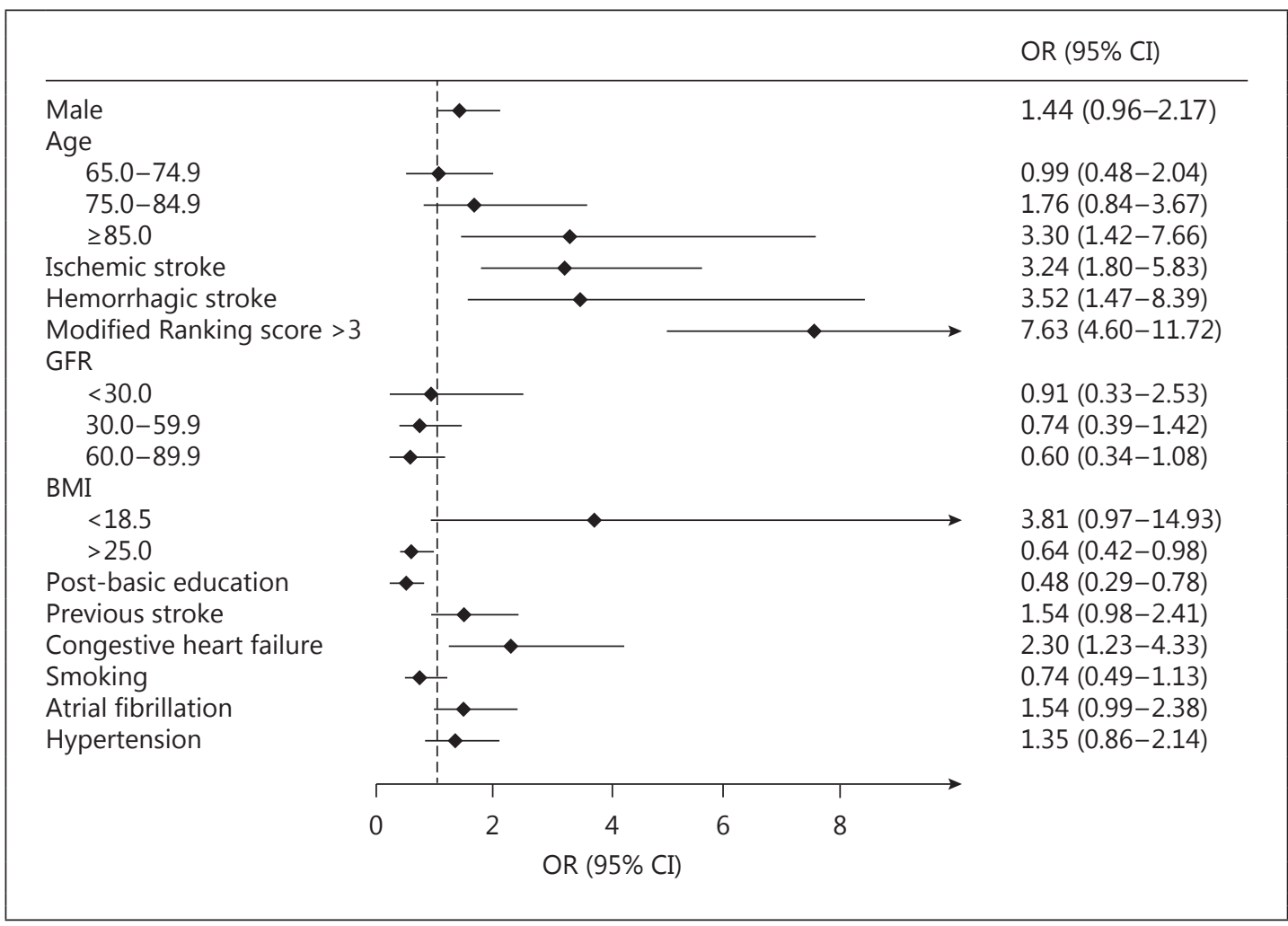

Fig. 3. Multivariate association with exclusion. Age $<65$ years, GFR $\geq 90 \mathrm{ml} / \mathrm{min}$, and BMI 18.5-24.9 were used as reference categories for age, GFR, and BMI, respectively.

Fig. 4. Cumulative one-year survival after discharge comparing included patients, excluded patients, and patients declining participation. Included vs. excluded: $\mathrm{p}<0.001$. Included vs. declining participation: $p=0.213$. Excluded vs. declining participation: $\mathrm{p}$ < 0.001 .

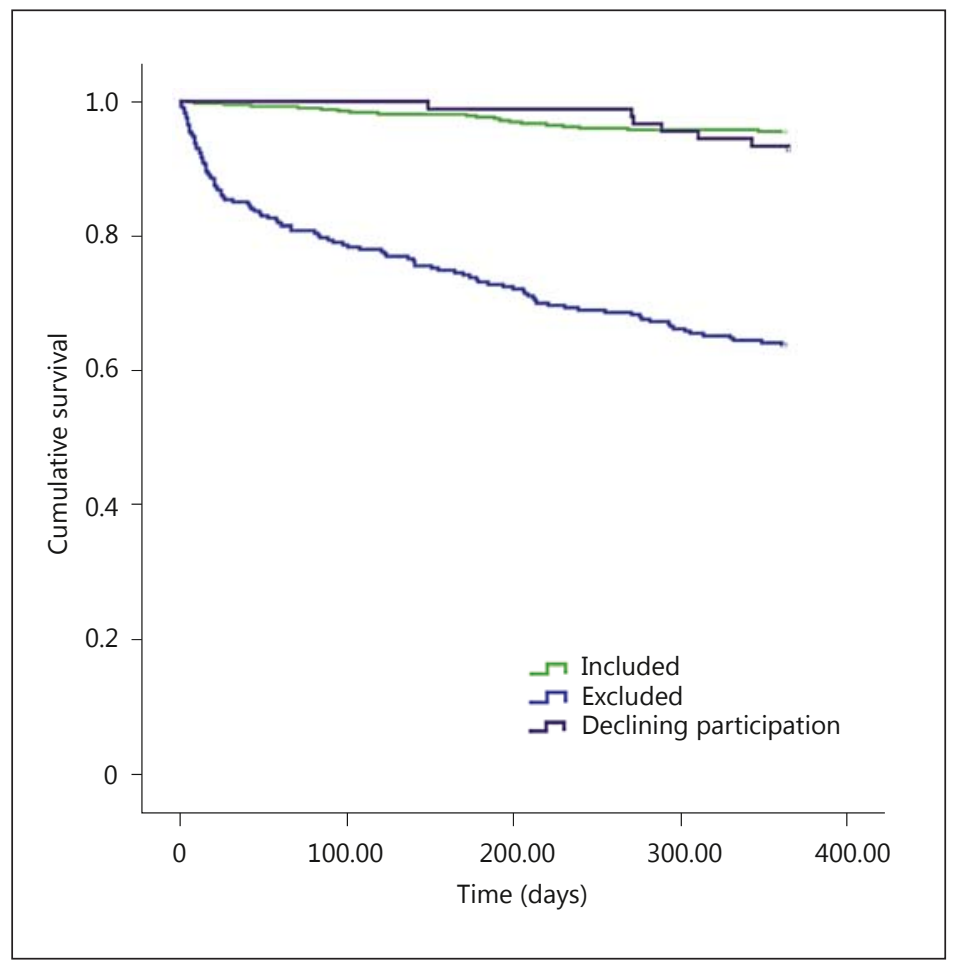


Irewall et al.: Implementation of Telephone-Based Secondary Preventive Intervention after Stroke and TIA

opportunity to study the implementation of a multifactorial secondary preventive program of follow-up on a population level. To our knowledge, this approach has not previously been studied.

Broadly implementing a method of secondary preventive follow-up in clinical practice requires that it be cost-effective as well as feasible in the targeted population. The telephonebased secondary preventive follow-up program studied in the NAILED stroke risk factor trial was designed with the intention to make participation as easy as possible, potentially minimizing the need for travels to visit the health care provider and supporting compliance by using an outreaching approach. When considered for inclusion into the secondary preventive follow-up program, $64.3 \%$ of the population was found to reach a physical and cognitive level sufficient to enable participation. However, $11.2 \%$ declined participation, resulting in a final participation rate of $53.1 \%$. This indicates that a secondary preventive program intended for implementation on a population level might only reach half of the intended population.

As illustrated by our data, the unselected stroke and TIA population constitutes an elderly group of patients with a high prevalence of comorbidity, often having a considerably reduced functional status. The representativeness of the study population in terms of age, proportion of stroke subtypes, comorbidity, and risk factors is supported by its generally good consistency with previously published data from the Swedish Stroke Register, Riks-Stroke, and the Swedish Hospital Discharge Register [21].

Most patients were excluded due to advanced disease, including severe stroke. In addition, we found that having an educational level at least equal to upper secondary school was negatively associated with exclusion, indicating a difference in stroke severity and comorbidity based on socioeconomic status (SES). Although not supported by the results of all studies [22], several publications confirm an association between stroke severity and low SES [2326]. In addition, low SES has been associated with worse prognosis in terms of post-stroke functional status [24] and mortality [23, 24, 27, 28]. When it comes to hypothesized differences in the burden of comorbidity and inequality within health care based on SES, studies show inconsistent results $[26,27]$ and mechanisms behind the association between SES and cerebrovascular disease remain poorly understood.

Since aphasia is common after stroke [29], a method of follow-up based on communication over the telephone could be of concern. In our study, the proportion excluded due to aphasia was, however, small, probably illustrating the fact that aphasia is seldom an isolated stroke sequela and is known to be associated with more severe stroke events [30]. It is therefore likely that some patients with aphasia were excluded not solely because of their speech disorder, but because of a generally low functional status due to the severity of the stroke or some other advanced disease. Also, the study population was a mixture of both stroke and TIA patients, strongly reducing the proportion of patients with expected communication problems due to permanent aphasia.

We believe that our study provides a reasonable estimate of what to expect in terms of participation rate when implementing an outpatient, secondary preventive, follow-up program on a population level. An increased participation rate could mainly be achieved by taking measures to reduce the proportion of patients declining participation.

In the present study, the education level was the only independent predictor associated with the decision not to participate, suggesting that education level is important for the implementation of secondary prevention, not only in terms of physical ability, but also when it comes to being motivated to participate. This finding is interesting since it could imply that more extensive patient education directed towards this particular group could generate increased participation in secondary preventive programs. It should, however, be pointed out that a statistical analysis does not provide information about causality, and the results should therefore be interpreted with caution. 
Having a stroke is known to be associated with a high one-year mortality rate $[2,28]$. The overall mortality rate among stroke patients in our population, taking into account those who died during hospitalization, is in agreement with previous population-based studies (data not shown) [28]. According to our results, the group of patients accounting for the vast majority of deaths is a group in which intensified secondary prevention in order to meet guidelines is very difficult to implement. It is also evident that a considerable proportion of deaths occur within the first months. We believe that these findings are important to consider in the implementation and assessment of secondary prevention, since they limit the realistic secondary preventive potential on a population level.

\section{Strengths and Weaknesses}

The population-based, prospective design of the NAILED stroke risk factor trial provided an excellent opportunity to study the implementation of secondary prevention on a population level, and we were able to include a relatively large population. During a 3-month test period, all patients diagnosed with a stroke or TIA were successfully identified, assuring that very few patients are likely to have been missed during the inclusion period. In addition, the descriptive data contained a very small number of missing values (with the exception of prior hyperlipidemia), and no patient was lost to follow-up.

Stroke and TIA are, by definition [19], clinical diagnoses. To ensure a consistent use of the diagnostic criteria, a second independent evaluation by a neurologist would have been preferable. This was, however, not performed, and could be considered a weakness of the study.

Additional variables related to SES would have been desirable in order to further analyze the associations found between educational level, the decision not to participate and exclusion. The group of patients declining participation did, however, constitute a fairly small sample, limiting the number of variables to be included in a multivariate model.

\section{Conclusion}

The implementation of secondary prevention in an unselected stroke and TIA population is greatly limited by the high prevalence of comorbidity and a considerable degree of disability. A large proportion of these patients are unable to participate even in simple secondary preventive follow-up, and the one-year mortality rate was substantially higher in this group. In addition, our results indicate that the education level is of importance for the clinical outcome as well as the motivation to participate in secondary preventive programs. Further research to investigate the mechanisms behind the associations between education level, clinical outcome and participation in secondary preventive programs is needed.

\section{Acknowledgements}

The authors gratefully acknowledge the study nurses whose indispensable efforts made this study possible. The study received funding from the Research and Development Unit, Jämtland County Council (Sweden).

\section{Disclosure Statement}

The authors have no conflict of interest to report. 
Irewall et al.: Implementation of Telephone-Based Secondary Preventive Intervention after Stroke and TIA

\section{References}

1 Touze E, Varenne 0, Chatellier G, Peyrard S, Rothwell PM, Mas JL: Risk of myocardial infarction and vascular death after transient ischemic attack and ischemic stroke: a systematic review and meta-analysis. Stroke 2005;36:2748-2755.

-2 Feng W, Hendry RM, Adams RJ: Risk of recurrent stroke, myocardial infarction, or death in hospitalized stroke patients. Neurology 2010;74:588-593.

-3 Mohan KM, Wolfe CD, Rudd AG, Heuschmann PU, Kolominsky-Rabas PL, Grieve AP: Risk and cumulative risk of stroke recurrence: a systematic review and meta-analysis. Stroke 2011;42:1489-1494.

4 Clark TG, Murphy MF, Rothwell PM: Long term risks of stroke, myocardial infarction, and vascular death in 'low risk' patients with a non-recent transient ischaemic attack. J Neurol Neurosurg Psychiatry 2003;74:577580.

5 Rothwell PM, Algra A, Amarenco P: Medical treatment in acute and long-term secondary prevention after transient ischaemic attack and ischaemic stroke. Lancet 2011;377:1681-1692.

6 Hackam DG, Spence JD: Combining multiple approaches for the secondary prevention of vascular events after stroke: a quantitative modeling study. Stroke 2007;38:1881-1885.

7 PROGRESS Collaborative Group: Randomised trial of a perindopril-based blood-pressure-lowering regimen among 6,105 individuals with previous stroke or transient ischaemic attack. Lancet 2001;358:1033-1041.

$>8$ Amarenco P, Bogousslavsky J, Callahan A 3rd, Goldstein LB, Hennerici M, Rudolph AE, et al: High-dose atorvastatin after stroke or transient ischemic attack. N Engl J Med 2006;355:549-559.

-9 Graham I, Atar D, Borch-Johnsen K, Boysen G, Burell G, Cifkova R, et al: European guidelines on cardiovascular disease prevention in clinical practice: executive summary. Fourth Joint Task Force of the European Society of Cardiology and other societies on cardiovascular disease prevention in clinical practice (constituted by representatives of nine societies and by invited experts). Eur J Cardiovasc Prev Rehabil 2007;14(suppl 2):E1E40.

10 Mancia G, Laurent S, Agabiti-Rosei E, Ambrosioni E, Burnier M, Caulfield MJ, et al: Reappraisal of European guidelines on hypertension management: a European society of hypertension task force document. J Hypertens 2009;27:2121-2158.

-11 Kotseva K, Wood D, De Backer G, De Bacquer D, Pyorala K, Keil U: Cardiovascular prevention guidelines in daily practice: a comparison of EUROASPIRE I, II, and III surveys in eight European countries. Lancet 2009;373: 929-940.

12 Amar J, Cambou JP, Touze E, Bongard V, Jullien G, Vahanian A, et al: Comparison of hypertension management after stroke and myocardial infarction: results from ECLAT1 - a French nationwide study. Stroke 2004;35: 1579-1583.

-13 Touze E, Coste J, Voicu M, Kansao J, Masmoudi R, Doumenc B, et al: Importance of in-hospital initiation of therapies and therapeutic inertia in secondary stroke prevention: implementation of prevention after a cerebrovascular event (IMPACT) study. Stroke 2008;39:1834-1843.

14 Alvarez-Sabin J, Quintana M, Hernandez-Presa MA, Alvarez C, Chaves J, Ribo M: Therapeutic interventions and success in risk factor control for secondary prevention of stroke. J Stroke Cerebrovasc Dis 2009;18:460-465.

15 Gaede P, Lund-Andersen H, Parving HH, Pedersen O: Effect of a multifactorial intervention on mortality in type 2 diabetes. N Engl J Med 2008;358:580-591.

16 Vale MJ, Jelinek MV, Best JD, Dart AM, Grigg LE, Hare DL, et al: Coaching patients on achieving cardiovascular health $(\mathrm{COACH})$ : a multicenter randomized trial in patients with coronary heart disease. Arch Intern Med 2003;163:2775-2783.

17 Neubeck L, Freedman SB, Briffa T, Bauman A, Redfern J: Four-year follow-up of the choice of health options in prevention of cardiovascular events randomized controlled trial. Eur J Cardiovasc Prev Rehabil 2011;18:278286.

18 Leistner S, Benik S, Laumeier I, Ziegler A, Nieweler G, Nolte CH, et al: Secondary prevention after minor stroke and TIA - usual care and development of a support program. PLoS One 2012;7:e49985.

19 Hatano S: Experience from a multicentre stroke register: a preliminary report. Bull World Health Organ 1976; 54:541-553.

20 Mooe T, Bergstrom L, Irewall AL, Ogren J: The NAILED stroke risk factor trial (nurse based age independent intervention to limit evolution of disease after stroke): study protocol for a randomized controlled trial. Trials 2013;14:5.

-21 Henriksson KM, Farahmand B, Asberg S, Edvardsson N, Terent A: Comparison of cardiovascular risk factors and survival in patients with ischemic or hemorrhagic stroke. Int J Stroke 2012; 7:276-281.

22 Grube MM, Koennecke HC, Walter G, Thummler J, Meisel A, Wellwood I, et al: Association between socioeconomic status and functional impairment 3 months after ischemic stroke: the Berlin Stroke Register. Stroke 2012;43:3325-3330.

23 Jakovljevic D, Sarti C, Sivenius J, Torppa J, Mahonen M, Immonen-Raiha P, et al: Socioeconomic status and ischemic stroke: the FINMONICA Stroke Register. Stroke 2001;32:1492-1498.

24 Arrich J, Lalouschek W, Mullner M: Influence of socioeconomic status on mortality after stroke: retrospective cohort study. Stroke 2005;36:310-314.

25 van den Bos GA, Smits JP, Westert GP, van Straten A: Socioeconomic variations in the course of stroke: unequal health outcomes, equal care? J Epidemiol Community Health 2002;56:943-948. 
26 Kerr GD, Higgins P, Walters M, Ghosh SK, Wright F, Langhorne P, et al: Socioeconomic status and transient ischaemic attack/stroke: a prospective observational study. Cerebrovasc Dis 2011;31:130-137.

27 Langagergaard V, Palnum KH, Mehnert F, Ingeman A, Krogh BR, Bartels P, et al: Socioeconomic differences in quality of care and clinical outcome after stroke: a nationwide population-based study. Stroke 2011;42:28962902.

-28 Kapral MK, Wang H, Mamdani M, Tu JV: Effect of socioeconomic status on treatment and mortality after stroke. Stroke 2002;33:268-273.

29 Dickey L, Kagan A, Lindsay MP, Fang J, Rowland A, Black S: Incidence and profile of inpatient stroke-induced aphasia in Ontario, Canada. Arch Phys Med Rehabil 2010;91:196-202.

30 Bersano A, Burgio F, Gattinoni M, Candelise L: Aphasia burden to hospitalised acute stroke patients: need for an early rehabilitation programme. Int J Stroke 2009;4:443-447. 